\title{
LA PREVENCIÓN COMUNITARIA DEL DELITO A TRAVÉS DE LA GOBERNANZA LOCAL ${ }^{1}$ THE COMMUNITY CRIME PREVENTION THROUGH LOCAL GOVERNANCE
}

\author{
Jorge Francisco Aguirre Sala \\ Universidad Autónoma de Nuevo León, México \\ jorge.aguirres@uanl.mx
}

\begin{abstract}
Cómo citar / Citation
Aguirre Sala, Jorge Francisco (2016). "La prevención comunitaria del delito a través de la gobernanza local". OBETS. Revista de Ciencias Sociales, 11(2): 383-418. doi:10.14198/OBETS2016.11.2.01
\end{abstract}

\section{Resumen}

El objetivo de este estudio es mostrar el mayor número de comunes denominadores en cuatro prácticas latinoamericanas exitosas de la prevención del delito. El análisis se hizo con una metodología cualitativa, de índole de diseño teórico y codificación axial. El marco teórico vinculó la participación ciudadana con la gobernanza para sintetizar las perspectivas social, ambiental y situacional de la prevención en el modelo comunitario. Los datos se recolectaron en indicadores de procesos y no de impacto. En los resultados destacan: la asociación entre ciudadanos y autoridades, la gestión de derechos sociales y el empoderamiento ciudadano a través del presupuesto participativo.

Palabras clave: participación ciudadana; gobernanza local; prevención del delito; seguridad pública.

\section{Abstract}

The objective of this study is to show the most number of common denominators in four successful Latin American practices in crime prevention. The analysis was done with a qualitative methodology of theoretical design nature and axial coding. The theoretical framework links the citizen participation with governance to synthesize the social, environmental and situational pre-

\footnotetext{
${ }^{1}$ Investigación elaborada con los apoyos económicos y académicos otorgados por el Instituto de Investigaciones Sociales de la Universidad Autónoma de Nuevo León y el programa de estímulos correspondiente al expediente \#14051 del Consejo Nacional de Ciencia y Tecnología (CONACYT) de la República Mexicana.
} 
vention prospects in the Community model. Data were collected on process indicators rather than impact indicators. The main results are: the association between citizens and authorities, the management of social rights and citizen empowerment through participatory budget.

Key words: citizen participation; local governance; crime prevention; public security.

\begin{abstract}
extended
The objective of this study is to show the most number of common denominators in four successful Latin American practices in crime prevention. The analysis was done with a qualitative methodology of theoretical design nature and axial coding. The theoretical framework links the citizen participation with governance to synthesize the social, environmental and situational prevention prospects in the Community model.

Consequently some distinctions are made: a) the conceptual differentiation of citizen participation: electoral and non-electoral participation. Within the non-electoral participation is: conventional participation, unconventional and disruptive. b) The types of crime prevention are distinguished: social, environmental and situational. The community prevention is exposed as a synthesis of the above. These are contrasted with models Broken Windows and Zero Tolerance. c) Governance and citizen participation to approach to the notion of governance through its historical development, comparing their characteristics with those of governability is performed. While in state governability mediates or colonizes institutionalization of citizen participation, at the governance citizen participation in public affairs is directly and brokering state formulas given in cooperatives; where new forms of regulation that require negotiation are present prevails and coordination. The state governability is vertical, even in procedures, weightings and agendas public consultations, while democratic governance seeks horizontality through deliberative consensuses that are not subject to hierarchical layers. In governability also it notes that the State assigns the conditions must have community networks (through regulations that constitute the structure and function of the Citizens Councils), in contrast to the governance of social networks have greater symmetry between citizens and the State. Also in the state governability it has the prerogative to take action and defining public policies; in contrast, governance seeks cooperation and to the delegation of state actions. The realization of the common good and the general interest is not in the state monopoly and is located in the interaction of government, the private sector and citizen participation. It also warns of the potential risks of governance to the scopes of neoliberalism.

The cases analyzed correspond to locations: Diadema, Brazil; The League of Emergency, Chile; Bogota, Colombia and Tlalpan, Mexico, in the form of local governance. Each was studied in the respective periods of application of their prevention programs: from 2000 to 2004 for Diadema; 2001-2003 for the League; 1993-2002 and 2007 to 2008 for Bogotá; 2010-2013 for Mexico.

Data were collected on process indicators rather than impact indicators. The
\end{abstract}


sources of information are documentaries and also come from in-depth interviews.

In the case of Brazil highlights the publication on Public Security from Prefeitura de Diadema (2006). The Chilean documentary information comes from Dammert and Lunecke (2004) and Candina (2006). For information from Colombia highlights the UN-Habitat program of the Mayor of Bogotá (2008), the corporate strategy of the National Police of Colombia (2010) and Angarita (2014). The information Tlalpan, in Mexico, comes from the Electoral Institute of the Federal District (2013). Latin America data come from Dammert (2005) and the United Nations Office on Drugs and Crime (2011). The main depth interviews were conducted with Ms. Karen Rosa Montiel Avila, police first rank and instructor at the University of Security Sciences in Mexico, who graduated from the School of Investigations Police of Chile; Dr. Benito Torres Escalante, specialization coordinator at the University of Security Sciences, who also given information and criteria for frame of reference in his work (Torres, 2005); Lieutenant Gerardo Gonzalez Espirícueta, actually retired member of Mexican army; Subcomisario Melquicedec Parra, actually retired member of the National Police of Colombia.

In the Diadema case of successful community prevention actions are listed: The creation of a municipal department of social policy and public security, public geo-referenced information for the registering of criminal activities, crime monitor jointly by authorities and citizens, the Municipal Council for Security and Crime Prevention, the definition of social and environmental policies aimed at school projects, campaigns delivery of firearms, thoughtful collection of toy weapons made by children and drug and alcohol awareness aimed at teenagers and young people. A comparative table between traditional police and community policing is showing, according to public perception.

In the League of Emergency case, from Chile, the outstanding actions were established under the following "lines": generate a more enjoyable environmental for neighbors' coexistence, opportunities for participation and dissemination of rights, expanding opportunities for recreation and expression. In Bogotá case the constant were: disarmament plan, rehabilitation of urban spaces, creating security fronts, family police stations, police professionalization for preventive surveillance and security pacts. In Colombian case also highlights the National Plan for Community Policing Quadrants, created by the National Police and executed with the table of minimum action required (TAMIR), among which are: networking citizens-police to give advice and weekly visits schools on issues of resistance and drug abuse, Schools of Public Safety, networks of support and solidarity and support networks and communications approaches to youth gang, older adults population in vulnerable conditions and "Civic youth Police".

A comparative table shows with most important common denominators. In Brazil, Chile, Colombia and Mexico cases there are a parallelism between the programs of community crime prevention and procedures of participatory budgeting. 
There are equivalences between the participatory budgeting process and community crime prevention: participatory budgeting starts with an approach from authorities to citizens at the moment the information, the upcoming implementation of the sharing mechanism and the corresponding call to present projects. This rapprochement is equivalent to contact and call for meetings with the public security authorities and the communities where intervention programs are generated in crime prevention.

Secondly, the preparation and presentation of projects in both processes is performed under the formula of governance: communication networks are established inter-organization, negotiation, and inter-institutionalization to design projects that complement each other government activities and those of the citizens. In both cases the projects are focused on solving problems and to this extent comply with "the reconstruction of the social control of the territory by those who live"; definition adopted for community crime prevention. As essential elements have community involvement, guidance for troubleshooting and decentralization.

Third, specific demonstrations planned in both processes have individualized matches: from the identification and registration of the participants, through their training, development of workshops, evaluation and certification of technical, legal and economic viability of the activities, formalizing agreements and commitments, to monitoring and recording of the actions themselves.

Conclusions show process indicators as evaluative elements for programs community crime prevention. Process indicators are: counting the number attending meetings and planning of the various programs counting interviews with government officials and participatory citizens, number of campaigns of all types of informants and reports of actions to recover and / or rehabilitate urban spaces, activities to protect environmental or situational prevention to people and goods through alarms, fences, lighting, etc.

Some negative aspects of community prevention are shown also: the criminalization "strange"; any differences are considered dangerous.

A further aspect to reassess in the governance of community prevention is the role of citizens delegate command and gender role inside the internal control of the police forces. This dimension opens a future line of research. In general, the criteria for successful programs in community crime prevention through local governance, are rooted in seven factors: 1) innovation, which includes citizen initiatives that, sometimes, never are imagined by the authorities; 2) the precision of the impact, that is, targeting to specific problems; 3) the association between individual citizens and groups with authority; 4) management, seeking the exercise and defense of social rights and the follow up complaints; 5) sustainability through technical, financial and legal viability of the projects approved by the Participatory Budgeting; 6) citizens or officials committed; and finally 7) empowerment of any member of the community (children and immigrants), not just citizens.

As a final corollary is clear that citizen participation cause maximum freedom with a minimum of punitive exercise of control institutions. Public security is harmonized with the legal security of each citizen. And undoubtedly contemporary community crime prevention through local governance with vanguard 
instruments of citizen participation, confirm Beccaria's wise thesis: "It is better to prevent crimes than to punish them".

\section{INTRODUCCIÓN}

La seguridad ciudadana es una responsabilidad ineludible para todo gobierno. Sin embargo, en muchas ocasiones las condiciones organizacionales, estructurales y económicas impiden al Estado garantizar la seguridad pública y concomitantemente otros derechos básicos como el derecho a la salud, la educación y las oportunidades laborales. En esas circunstancias los gobiernos permiten o promueven iniciativas privadas o ciudadanas bajo la tutela del Estado para elevar los niveles de salud, educación y empleo. La seguridad no ha sido la excepción. Pero el uso de la fuerza pública es un derecho exclusivo del Estado, por ende, una de las estrategias gubernamentales consiste en establecer propuestas de prevención comunitaria del delito con la coparticipación de la ciudadanía bajo el esquema de la gobernanza.

Por lo anterior, el objetivo capital de este estudio estriba en analizar y hallar los elementos que constituyen un común denominador en las prácticas exitosas de la prevención comunitaria del delito ejercida por la gobernanza de tipo local. Ello supone que la prevención comunitaria del delito, a través de la gobernanza local, exige un alto y constante nivel de institucionalización de la participación ciudadana. Para comprender dicho fenómeno se explica, como marco teórico, las diferenciaciones conceptuales de la participación ciudadana y la noción de gobernanza guiadas a la prevención del delito. Desde este marco teórico se establecer la metodología para el análisis que permite hallar los comunes denominadores de la prevención en los casos exitosos a escala local. El análisis y los hallazgos de los elementos comunes proveen recomendaciones focalizadas que permitirán elevar la calidad de la seguridad pública. Dichos elementos no proveen datos para establecer correlaciones con la disminución de las tasas delictivas y obtener evidencias con los indicadores de impacto. No obstante, los elementos comunes resultan ilustrativos como indicadores de procesos e indicadores operativos.

\section{METODOLOGÍA}

Para obtener el mayor número de comunes denominadores en las prácticas exitosas de la prevención del delito, se efectúa un análisis con metodología cualitativa de índole de diseño teórico fundamentado (Hernández-Sampieri, Fernández-Collado y Baptista, 2006: 687 y ss.). Inicialmente se conceptualiza la prevención bajo tres enfoques: la perspectiva social, ambiental y situacional. 
Las tres propuestas pueden sintetizarse en la prevención comunitaria, siguiendo el proceso metodológico de "codificación axial" de Strauss y Corbin (1990). Ello permite ligar la prevención comunitaria a la gobernanza. Establecido ese vínculo, se sigue la metodología cualitativa de teorías sustantiva o de rango medio (Glaser y Strauss, 1967) para aprovechar la codificación selectiva y axial de la función sintetizadora 'prevención comunitaria-gobernanza' con los niveles primarios (población general) y secundarios (población de victimizadores) de prevención, pues en ellos puede involucrarse la participación ciudadana. Se excluye el nivel terciario (victimarios), que corresponde a los procesos penales de readaptación y rehabilitación para evitar las reincidencias de los infractores, porque la participación ciudadana no tiene potestad directa para intervenir en dichos procesos.

La muestra de las prácticas exitosas se delimita a cuatro experiencias latinoamericanas reconocidas por la comunidad de expertos y académicos en materia de seguridad. Aunque ningún caso fue posible galardonarlo con el premio "Gobernarte" del Banco Interamericano de Desarrollo, porque el premio se estableció a partir del año 2013. Sin embargo, Brasil, Colombia y México son los países permanentemente coincidentes entre los premiados y la muestra aquí elegida los incluye sumando un caso de Chile. Se prefiere la muestra latinoamericana porque, al adoptar la prevención comunitaria, se excluyen los modelos de origen anglosajón conocidos como Broken Windows y Zero Tolerance, que también se contrastan en el marco teórico.

Los casos de la muestra conciernen a escalas municipales para guardar consistencia con el modelo comunitario y corresponden a Diadema, Brasil; La Legua de Emergencia, Chile; Bogotá, Colombia y Tlalpan, México. Cada uno se estudió en los respectivos períodos de aplicación de sus programas de prevención: 2000 a 2004 para Diadema; 2001 a 2003 para La Legua; 1993 a 2002 y 2007 a 2008 para Bogotá; 2010 a 2013 para México.

La recolección de datos se establece para los indicadores de procesos y de operativos y, por no tratarse de una metodología cuantitativa, se excluyen los de impacto. Ello obedece al propósito de destacar las intervenciones de participación ciudadana en vinculación con la gobernanza contra el delito e ilustrar las propuestas, estrategias y tácticas, más allá del mero registro estadístico (exactamente como sucede en la georreferenciación preventiva del delito). Las fuentes de información son documentales y también provienen de entrevistas a profundidad.

La información documental se halla consignada en la bibliografía basada en el establecimiento, publicación y divulgación de resultados de los programas. Para el caso de Brasil destaca Kahn (2004) y la publicación sobre seguridad 
pública de la Prefeitura de Diadema (2006). En el ámbito chileno la información documental procede de Dammert y Lunecke (2004) y Candina (2006). Para Colombia destacan como fuentes informativas el programa UN-Habitat de la Alcaldía de Bogotá (2008), la estrategia institucional de la Policía Nacional de Colombia (2010) y Angarita (2014). La información general de México tiene sus fuentes en el manual del gobierno municipal de Puebla (2012) y Hernández y Zepeda (2015). De Tlalpan los datos proceden del Instituto Electoral del Distrito Federal (2013). De Latinoamérica en general los datos provienen de Shaw (2001), Dammert (2005) y la Oficina de Naciones Unidas contra la droga y el delito (2011). De entre las entrevistas a profundidad destacan las participaciones de la Lic. Rosa Karen Ávila Montiel, policía de primer rango e instructora de la Universidad de Ciencias de la Seguridad en México, quien es egresada de la Escuela de Policía de Investigaciones de Chile; la participación del Dr. Benito Torres Escalante, coordinador de especializaciones en la Universidad de Ciencias de la Seguridad, de quien también se ha tomado información y criterios de marco referencial a partir de su obra (Torres, 2005); del teniente en retiro del ejército mexicano Gerardo González Espirícueta; y la participación del Subcomisario Melquicedec Parra, actualmente miembro en retiro de la Policía Nacional de Colombia. Del resto de las entrevistas a profundidad se agradece la disposición de todo el personal militar, policial y de trabajo social que participó.

Los resultados, discusión y conclusiones se exponen según le metodología de Hernández-Sampieri, Fernández-Collado y Baptista, (2006: 731-734). Los resultados se exhiben por el modelo desarrollado de prevención comunitaria que incluye la prevención social, ambiental y situacional en una matriz que despliega a cada localidad de la muestra. También por la metodología narrativa que hace referencia a los niveles de intervención. Las discusiones se presentan por la metodología concerniente a las cuestiones futuras que deben ser analizadas. Las conclusiones se presentan validando la exigencia de institucionalizar la participación ciudadana.

\section{MARCO TEÓRICO: LA PARTICIPACIÓN CIUDADANA Y LA GOBERNANZA EN LA PREVENCIÓN DEL DELITO}

Si la participación ciudadana no incrementara la calidad de vida, -y con ella la calidad de la seguridad ciudadana y pública-, carecería de sentido. Particularmente la participación ciudadana puede incrementar la calidad de vida al abocarse a disminuir los actos delictivos comunitarios o llamados del "fuero común". Los quehaceres ciudadanos serían ridículos si, como indica el reputado constitucionalista norteamericano Ackerman: "la vida política no es más 
que una de muchas diversiones en la continua búsqueda de la felicidad" (1999: 207). Cuando se trata de la seguridad ciudadana y de la prevención delictiva, la participación ciudadana no es una fiesta, ni siquiera un divertimento en la vida política.

Si se adopta la clasificación de Martí I Puig, Ortega y Somuano (2011) que categorizan las participaciones ciudadanas en electorales y no electorales para hacer hincapié en que éstas últimas incluyen a la participación convencional, la no convencional y la disruptiva, (ampliando la distinción conceptual establecida por Barnes y Kaase (1979)) entonces se aceptará que la participación no electoral convencional es la más apropiada para la prevención del delito en gobernanza. La participación no convencional (mítines, caravanas, peticiones, reparto de volantes) y la disruptiva (ocupación de plazas y edificios públicos, bloqueos, intentos violentos de derrocamiento) muestran insatisfacción y rechazo hacia el sistema político y el estatus quo. En contraste, la participación convencional (actividades comunitarias, contacto con las autoridades, militancia en organizaciones civiles, conformación de comités o comisiones ciudadanos, etc.) valoran positivamente la organización política y social y se adhieren a sus reglas (Vallès, 2000) y, por ello mismo, desean proceder dentro de la legalidad y procuran que todos los miembros de una comunidad también así lo hagan de manera permanente. Es decir, la participación convencional apunta a desarrollar sus actividades estableciendo procedimientos de manera institucional, sobre todo para adquirir una estructura organizacional y los medios para entrar en contacto con las administraciones gubernamentales en las cuales todavía depositan amplia credibilidad (Ganuza y Francés, 2015).

La participación ciudadana convencional institucionalizada tiene como propósito influir en el gobierno, con interacciones ante y con el Estado planteadas desde ambos lados de la interacción (Organization for Economic Cooperation and Development (OECD), 2011). Busca superar los obstáculos de facto que impiden al Estado cumplir con la misión de garantizar la seguridad pública. Tal es la cooperación de la gobernanza local en la prevención comunitaria del delito. La participación ciudadana convencionalmente institucionalizada en los procesos de gobernanza es el último cabo de buena esperanza por el cual los ciudadanos no han perdido la confianza de influir, -estructural y por tanto, permanentemente-, en asuntos gubernamentales que generan mayor calidad en la seguridad ciudadana y pública. En contraste, la participación no convencional y la disruptiva, en relación al delito, paradójicamente incurren en violaciones al orden público o la ley. Ambas, en más de una ocasión se denigran al tomar la justicia por propia mano y cuando ello ocurre, la mayoría de las veces las situaciones desembocan en linchamientos y otros actos de bar- 
barie colectiva. Por ende, la participación ciudadana de tipo convencional -institucionalizada a través de la gobernanza local-, constituye la esencia de las movilizaciones que pueden elevar la calidad de la seguridad ciudadana a través de la prevención comunitaria del delito.

Si se deslinda la participación ciudadana convencional de las actividades que muestran insatisfacción con la organización política, entonces se comprenderá que la acción ante el Estado se transforma en interacción con el Estado y no en enfrentamientos. A ello debe llamársele gobernanza y concebirse, en buena parte, como una instrumentación del poder ciudadano en el gobierno. La noción de gobernanza en sí misma ha sido ambigua por las circunstancias de su nacimiento histórico, pues se planteó también en relación al desarrollo económico y los vínculos con el mercado. El Diccionario de la Real Academia Española de la Lengua incluyó una nueva definición de gobernanza en su $21^{\mathrm{a}}$ edición. Así, gobernanza es el "arte o manera de gobernar que se propone como objetivo el logro de un desarrollo económico, social e institucional duradero, promoviendo un sano equilibrio entre el Estado, la sociedad civil y el mercado de la economía". A pesar de los vínculos con los poderes de facto,-como el mercado neoliberal que la hacen vulnerable a los intereses de grupos hegemónicos-, la gobernanza apunta a un nuevo gobierno que abandona el férreo control monopólico por parte del Estado. Por tanto, no sigue al pie de la letra la jerarquía de las escalas gubernamentales, sino que opera en interacción de redes autónomas con estructuras y procesos de información, enlace y co-decisión. Puede decirse entonces que:

"la gobernanza está constituida por las normas y reglas que pautan la interacción en el marco de redes de actores públicos, privados y sociales interdependientes en la definición del interés general en entornos complejos y dinámicos. La gobernanza se asocia a una mayor implicación de actores no gubernamentales en el diseño e implementación de las políticas públicas y, al fin y al cabo, en la definición del interés general" (Cerrillo, 2005: 9)

En consecuencia, la gobernanza posee mayor capital social y capacidad de participación ciudadana que la mera gobernabilidad. Busca nivelar la asimetría de poder que los partidos políticos autoritarios cooptaron al convertirse en bloques herméticos y cuya misión se redujo a la eficacia de la contienda electoral. Ello les conllevó un alejamiento de las capacidades ciudadanas en el ámbito local, vinculo que es necesario para resolver las cuestiones públicas en la escala comunitaria, aplicar soluciones desde los intereses y recursos de ciudadanos particulares y disolver conflictos concretos a través del consenso. Es decir, los partidos políticos han quedado rebasados por no permitir el ejercicio del poder en las escalas allende a sus fronteras, en variadas esferas de alta complejidad donde no son los únicos actores sociales y por no poseer alcance transversal. 
Otras distinciones entre la gobernabilidad y la gobernanza se deducen a partir del ensayo de Paniagua, Borunda y Camargo (2012) y la compilación de los 10 textos de referencia fundacional que realizó Cerrillo (2005). Mientras que en la gobernabilidad se impone la institucionalización estatal que mediatiza o coloniza la participación ciudadana, en la gobernanza la participación ciudadana en asuntos públicos es directa y la intermediación del Estado se da en fórmulas cooperativas donde se hacen presentes nuevas formas de regulación que requieren negociación y coordinación. En la gobernabilidad se instaura la verticalidad estatal, aún en los procedimientos, ponderaciones y agendas de la consultas ciudadanas, mientras que en la gobernanza se procura la horizontalidad democrática a través de los consensos deliberativos que no están sujetos a estratos jerarquizados. En la gobernabilidad también se observa que el Estado asigna las condiciones que deberán poseer las redes ciudadanas (a través de los reglamentos que constituyen la estructura y función de los Consejos Ciudadanos), en contraste en la gobernanza las redes sociales poseen mayor simetría entre los ciudadanos y el Estado. También en la gobernabilidad el Estado tiene la prerrogativa exclusiva para tomar acciones y definir políticas públicas; en contraste, la gobernanza procura la cooperación y hasta la delegación de acciones estatales. La realización del bien común y de los intereses generales no se encuentra en el monopolio del Estado y se ubica en la interacción del poder público, la iniciativa privada y la participación ciudadana. Prats acota que:

"La Comisión Europea, en la preparación de su Libro Blanco sobre la Gobernanza de 2001, adoptó la visión de que el modelo de gobernanza por redes se adaptaba mejor que los modelos jerárquicos tradicionales al contexto socioeconómico actual, caracterizado por los cambios rápidos, la fragmentación y problemas de políticas interconectados y complejos" (2005: 162).

Y ello se debió a que las recientes versiones de la gestión pública resultaron insuficientes porque los departamentos ejecutivos o agencias del gobierno no pudieron abarcar monopólicamente el conocimiento de especialidad para enfrentar los problemas y porque los desafíos (sobre todo los de seguridad, cohesión social y calidad de vida) requieren soluciones transversales y las jurisdicciones departamentales de la gestión pública están limitadas sólo a realizar las acciones facultadas que jurídicamente les compete.

Así pues, la gobernanza nace de la necesidad de crear estructuras y procesos de interacción entre las instancias ciudadanas afectadas y el Estado. Busca adoptar responsabilidades comunes y diferenciadas al constituir una forma de decidir con pluralidad de actores en tendencias de mayor horizontalidad y equilibrio. Por tanto, la gobernanza debe ejercerse con los principios democráti- 
cos de transparencia, participación, subsidiariedad horizontal, complementariedad y proporcionalidad entre actores públicos y privados.

Tomando en cuenta lo anterior, puede compilarse un inventario de elementos de la gobernanza que apuntan a modelar los programas de prevención comunitaria. Dicho inventario requiere, en primer lugar, liberar a la gobernanza del yugo de una mera administración pública o nueva gestión estatal. Es decir, la participación de actores públicos y privados (empresas, organizaciones no gubernamentales, asociaciones no lucrativas, entidades que agrupan a profesionales, etcétera) no sólo proveerán servicios, sino también definirán las políticas públicas y los valores que pautan su evaluación. Entre esos valores se encuentran la acción en red, el sistema socio-cibernético (tomando este término en su sentido etimológico), la inter-organización cooperativa que provoca el reequilibrio de las asimetrías del poder y la actualización electrónica del gobierno ante las demandas de la sociedad digital que le exigen mayor eficacia y eficiencia.

Otro elemento de la gobernanza, más allá de la mera cooperación entre los sectores privado y público, es la prestación de algunos servicios públicos por instancias privadas. Desde un punto de vista crítico contra el liberalismo, esta característica implica el riesgo de desplazar al Estado democrático por las funcionalidades del libre mercado. Debe evitarse que los gobiernos queden reducidos a meras agencias de gestiones y se sometan al servicio de los actores con mayores recursos económicos. La gobernanza, -para evitar su declive y el de la soberanía de sus actores-, debe constituirse con elementos de diversidad, complejidad y dinamismos suficientes para incluir todos los intereses en su búsqueda del mayor bien común. Es decir, debe evitar que la antigua uni-direccionalidad gubernamental del Estado sea sencillamente sustituida por la uni-direccionalidad de grupos hegemónicos de capital.

Las fórmulas iniciales de gobernanza; autogobierno, cogobierno y gobierno jerárquico que Kooiman (2005) había propuesto e inspiraron a muchos teóricos, quedan rebasadas por la participación ciudadana. Significativamente esto acontece al elevar el nivel de vida por medio de la prevención del delito. Se busca la minimización de un gobierno formal y la maximización de los objetivos compartidos nacidos de la soberanía. La soberanía es el fundamento último, delegada en el Estado, para instrumentalizar la fuerza pública. Es decir, la prevención comunitaria del delito encarna la metáfora de Osborne y Gaebler (1992) más el dirigir que el remar, que distingue muy bien la gobernanza de la gobernabilidad (sobre todo del poder ejecutivo). Se ha de distinguir la participación de la ciudadanía de la mera obediencia ciega a la autoridad encargada de velar por el orden público y la paz social (llámese policía, ejército, 
marina o armada). En pocas palabras: la prevención comunitaria del delito, modalidad de la gobernanza local, descentraliza la autoridad en la medida que el poder es transmitido a los ciudadanos con el efecto de 'menos gobierno' (remo) y 'más gobernanza' (dirección).

La noción de gobernanza, no obstante, recibe una crítica que también interpela a la prevención comunitaria del delito. Ambas -gobernanza y prevención comunitaria- enfatizan los procedimientos y/o la deliberación y descuidan la eficacia de los resultados (Peters y Jon, 2005: 123 y ss). Además, se alega que:

"el desempeño mejora cuando las decisiones se focalizan en los productos y resultados más que en los insumos y procedimientos -y que además- la gobernanza no es un sustituto del gobierno, sino una modalidad de gobernación con el gobierno... que replantea sus roles, formas organizativas y procedimentales" (Prats, 2005: 152 y 171).

Y aún más severamente Aguilar critica:

"Las evidencias disponibles conducen más bien a sostener la hipótesis de que la gobernanza nueva tiene su factor causal crucial en el enlace entre el proceso gerencial y el proceso politico-civil que ha caracterizado a las reformas institucionales... El retorno a la gobernanza por el gobierno... es una opción tal vez imaginable pero no viable" (2007: 11).

Ante estas críticas la gobernanza requiere consolidarse de manera efectiva y eficaz. Y por obedecer también a los intereses básicos del bien común, se propone una versión específica: la modalidad de la prevención comunitaria del delito con base en la participación ciudadana.

Un primer acercamiento a la prevención del delito lo ofrece Van Dijk: “...todas las políticas, medidas y técnicas, fuera de los límites del sistema de justicia penal, dirigidas a la reducción de las diversas clases de daños producidos por actos definidos como delitos por el estado" (1990: 205). A partir de este concepto pueden precisarse diversas formas de prevención. En primer lugar, las políticas, medidas y técnicas referidas en la definición de Van Dijk derivan en tácticas situacionales, ambientales, sociales y comunitarias. Las dos primeras apuntan a la reducción de oportunidades para la realización de los actos que según los códigos penales tipificarían como delitos. Ambas tienen un doble enfoque: la atención puede dirigirse a evitar que haya agentes del delito y/o apuntar a quienes pudieran ser pacientes (víctimas) del delito. En el primer enfoque las acciones se dirigen hacia la disuasión encaminada a los potenciales victimizadores y la reinserción social para los victimarios. En el segundo enfoque se haya la prevención del delito en manos de la posible víctima, prevención que no logra rebasar la táctica situacional y/o ambiental. La preven- 
ción situacional se alcanza al implementar obstáculos mecánicos y/o electrónicos para disuadir al delincuente bajo las premisas de la teoría de la elección racional, es decir, bajo la fórmula costo/beneficio o riesgo/éxito implicadas en la labor de delinquir. La prevención ambiental se logra en la media en que las realidades arquitectónicas y urbanísticas reducen las oportunidades del delito en función al control de acceso, la vigilancia y el refuerzo territorial (Hernando, 2008).

La mayor dificultad está en los retos de la prevención social, pues considera que el crimen es causado por las desigualdades sociales. En consecuencia, las soluciones estriban en mejores salarios, menores tasas de desempleo, mayor educación y en general condiciones de satisfactoria calidad de vida. Quizá el primero en postular este tipo de prevención fue Alexandre Lacassagne (18431924) para quien, en palabras de Núñez: "el delito no era consecuencia de un atavismo en el hombre [como lo había propuesto Ferri, Garófalo y Lombroso] sino que atribuye al medio social un papel importante en la aparición de conductas criminales" (2011: 60). Ideas similares y ampliadas que según Núñez (2011: 66 y 67) también pueden encontrarse en las propuestas criminológicas de Robert K. Merton, Glueck y Edwin H Sutherland. El enfoque de la prevención social centra su atención en: fortalecer los lazos familiares de los infractores, haber tenido educación por unos buenos padres que ejercieron la vigilancia adecuada, haber asistido a una escuela con disciplina humanitaria y atenta a evitar la deserción; y sobremanera, contar con un medio social que ofrece oportunidades laborales decentes y opciones sanas para el goce del tiempo libre. Pero no todo en la vida es miel sobre hojuelas.

Por tanto, deben considerarse las tácticas comunitarias de la prevención delictiva. La prevención comunitaria se construye como híbrido de las versiones situacionales, ambientales y sociales. Sozzo la define como: "técnicas de intervención que están orientadas a la comunidad/vecindario en lugar de estar orientadas a las potenciales víctimas o a los potenciales ofensores" (2000: 37). Esta concepción presenta otro matiz también de doble enfoque, y ello debe aprovecharse con ilación desde la participación ciudadana y la gobernanza hasta mecanismos de participación que en pocas ocasiones se han implementado en función de la prevención. El doble enfoque, en el caso comunitario, se revela porque la misma comunidad es el objeto de las intervenciones y simultáneamente es el sujeto o agente de las mismas. La prevención se dirige a evitar, -como tarea de las autoridades de seguridad pública-, que se cometan delitos y al mismo tiempo a evitar, -como responsabilidad de los ciudadanos-, que las personas se expongan y sean víctimas de los delincuentes. Para obviar el dilema objetivismo-paciente de la táctica preventiva versus subjetivismo-agente 
de la intervención, Sozzo amplifica su teorización con una apreciación de Pavarini (1994), que puede expresarse con una paráfrasis: 'la prevención comunitaria busca reconstruir el control social del territorio por parte de quien lo habita'. Esta sería una definición de prevención comunitaria suficiente si explícitamente involucrara al Estado y a la ciudadanía en disposición de gobernanza para el primero y en condiciones de actividades de participación para la segunda. De cualquier manera, en la 'reconstrucción del control social del territorio por quien lo habita', Sozzo y Pavarini vislumbraron una idea clásica rescatada recientemente: el vínculo vital entre hábitats-hábitos y habitantes.

Permítase una digresión cultural de tres párrafos para ilustrar el vínculo vital entre el hábitat de una comunidad y su importancia para los hábitos de los habitantes de la misma. En los orígenes más arcaicos de la lengua griega, la palabra ethos (Liddell \& Scott, 1996, entrada: ethos) no hacía referencia a la ética, sino a la madriguera; la morada donde habita un animal. Cuando esta idea se extendió al humano, entonces la ética significó la morada del hombre. Con el tiempo, el sustantivo ethos también se uso como verbo y ambos, sustantivo y verbo, se instauraron en el latín con los vocablos hábitat y habitar, respectivamente.

Por razones de adaptación el hábitat incide en las maneras de habitarlo y transformarlo, y cuando ello se convierte en algo regular se producen los hábitos. Los cuales, al constituirse en costumbres, configuran el ethos del comportamiento. De esta manera hábitat y hábitos marcan la conducta, es decir, causan el carácter de los habitantes y, a su vez, los hábitos también inciden en los hábitats.

De lo anterior se sigue que los hábitos y comportamientos sociales o éticos no existen en situaciones aisladas de sus ambientes (hábitats), ni de los demás habitantes; y la suma de ambientes y habitantes es la comunidad en vista a la cual se aboca la gobernanza para lograr la prevención delictual. De ello también se extraen las siguientes consecuencias: habitar en una comunidad implica un hábito o costumbre con cualidades sociales y éticas significativas ante la idea del delito que poseen los demás habitantes; los hábitats pueden transformar los hábitos y en consecuencia, las comunidades (hábitat, hábitos y habitantes) pueden transformar la incidencia delictual.

Para reconstruir el control social del hábitat por los propios habitantes existen varias acciones recomendables. Y lo mejor sería adquirirlas como hábitos. Desde el punto de vista de la gobernanza deben alinearse los intereses individuales, colectivos y del Estado. Tanto la gobernanza como la prevención comunitaria del delito requieren de las redes de gestión inter-organizacional y autoreguladas. Si bien es cierto que los ciudadanos comunes no están reconocidos 
legalmente para hacer uso público de sus fuerzas, los pactos de gobernanza les otorgan legitimidad para dirigirlas por vías deliberadas y consensuadas. "Menos remo y más dirección" provoca que el ciudadano privatista abandone las políticas públicas de arriba hacia abajo y se convierta en el ciudadano público (denominaciones que pertenecen a Ackerman, (1999)) que procura dirigir la política desde abajo hacia el resto de comunidad.

Cuando las estrategias se deliberan y consensuan en el conjunto de agentes privados (individuales y colectivos) y públicos, entonces se puede contar efectivamente con los recursos ciudadanos realmente disponibles. De la deliberación y el consenso -propios de la gobernanza-, se sigue la organización de actividades preventivas. En América Latina ello ha causado programas ejemplares: en Diadema, Brasil; Bogotá, Colombia; La Legua, Chile; Tlalpan, México. Seguramente estas campañas no son tan famosas como aquellas generadas en los Estados Unidos de Norteamérica cuyos slogans pasaron a la historia como leyendas imposibles de falsear: Broken Windows y Zero Tolerance. La diferencia entre éstas y aquéllas es crucial, pues mientras en las actividades preventivas el Estado y la comunidad están involucrados en intereses comunes; en las campañas norteamericanas el único interés es la seguridad pública sin atención a las dimensiones privadas. En las campañas norteamericanas el Estado es el único actor involucrado ya que los ciudadanos sólo son la fuente de financiamiento de las fuerzas públicas. En las actividades preventivas comunitarias la seguridad pública alcanza a la seguridad ciudadana porque incide en la vida privada al evitar consumos riesgosos de droga, abusos sexuales o violencia intrafamiliar y además promueve el desarrollo comunitario y humano. Las actividades ciudadanas son preventivas, mientras que las campañas norteamericanas, -si bien pretenden mostrarse preventivas-, en realidad sólo son actitudes punitivas de reacción por parte de la fuerza pública que desea la baja delictiva en zonas predeterminadas y no considera el riesgo de desplazar el delito a los hábitats vecinos.

Broken Windows nació de las ideas que James Q. Wilson y George L. Kelling publicaron en 1982 en un artículo del mismo título (Wilson y Kelling, 1982) y que fueron secundadas por el mismo Kelling y Catherine Coles en 1998 en el texto Fixing Broken Windows: Restoring Order and Reducing Crime in Our Communities (Kelling y Coles, 1998). La tesis central cae en la falacia de la cuesta resbalosa, pues consideran que al dejar impune conductas antisociales mínimas en un vecindario (por ejemplo, la presencia de graffiti o de basura en la vía pública), en la misma zona se presentará un aumento alarmante de las mismas conductas y un incremento de acciones indeseables (mendicidad, prostitución) hasta llegar a delitos mayores (secuestros, terro- 
rismo, etcétera). Así, suponen que la reacción firme y dura de parte de las instituciones de seguridad pública en lo leve prevendrá el acontecimiento de lo grave.

Mientras que Zero Tolerance (expresión popularizada a partir de 1994 siguiendo la idea Broken Windows, pero que se tomó del reporte de New Jersey publicado en 1973 bajo el título: ), obedece a una idea mayormente punitiva: proceder con la máxima severidad e inmediatez, -sin ningún tipo de atenuantes-, a castigar las más mínimas infracciones. Suponiendo que con ello se detendrán las marejadas del crimen.

Las diferencias entre actitudes punitivas criminalizadoras y las acciones comunitariamente productivas explican por qué los ciudadanos prefieren la actuación preventiva, dado que se perfila hacia las causas integrales del delito (situacionales, ambientales y sociales) y no sólo a mitigar o amedrentar sus antecedentes.

La prevención comunitaria, como especie de la gobernanza, no sólo genera programas y actividades contra el delito, sino que apunta a los aspectos del desarrollo humano que también lo previenen. Y en ese sentido genera una empatía que redunda en verdadera cooperación, la cual se complementa con la asignación de quienes serán los encargados y responsables de cada acción. Así, sin erogaciones para el Estado para efectos de estructuración organizacional (no así para la operación de programas), se crean instituciones mediadoras entre la ciudadanía y las instancias de gobierno. No obstante, los financiamientos para los programas y actividades también podrían darse en el contexto de una gobernanza local. Tal es el caso del contemporáneo mecanismo de participación ciudadana denominado "Presupuesto participativo" que se ha aplicado en algunos municipios de Brasil, algunas zonas de Bogotá y delegaciones de Ciudad de México.

\section{DIADEMA, BRASIL}

Diadema estaba en la cúspide de homicidios y de delitos de bajo impacto entre las municipalidades de Sao Paulo en el año 2000. Para revertir la situación las autoridades implementaron un programa de prevención comunitaria complementado con estrategias de salud pública, control policial, cultura de la legalidad y modificaciones en el control policial. Coadyuvante a estas acciones se aplicó el Presupuesto participativo.

En lo que corresponde a la prevención comunitaria de Diadema, caben destacar las siguientes acciones (Oficina de Naciones Unidas contra la droga y el delito, 2011: 84): la creación de un Departamento municipal de políticas sociales y seguridad pública. Departamento que surgió con elementos implícitos 
de gobernanza en la medida que recibía información ciudadana para el levantamiento georreferenciado de las actividades delictivas y estableció el seguimiento de las mismas de manera conjunta con autoridades y ciudadanos. Otra acción fue el establecimiento del Consejo Municipal para la Seguridad y la Prevención del Delito, que proponía las políticas más inmediatas para los programas de prevención, mostrando con ello una característica esencial de la gobernanza aunando la definición de políticas sociales y ambientales dirigidas a proyectos escolares. Entre otras experiencias exitosas cabe enumerar las campañas de entrega de armas de fuego, la recolección reflexiva de armas de juguete efectuada por los niños y la sensibilización sobre drogas y alcohol dirigida a adolescentes y jóvenes.

Aunque no existen estudios que muestren la correlación directa entre el Presupuesto participativo y la baja en la tasa delictiva en el caso de Diadema para los períodos 2000 a 2004, puede conjeturarse la vinculación. Muchos de los procedimientos de la prevención comunitaria coinciden con etapas y acciones del Presupuesto participativo. Y no sólo los procedimientos de planeación y ejecución, sino que también las características políticas y sociales. El Presupuesto participativo y la prevención comunitaria son acciones auto-reguladas, participativas sobre la línea generativa del capital social, aplicadas bajo el modelo de gobernanza y con impactos inmediatos en la mejora de la calidad de vida atendiendo a ésta por asuntos temáticos y puntuales. Sin embargo, el reconocimiento explícito entre el Presupuesto participativo y la prevención comunitaria apenas se ha insinuado, pues los Presupuestos participativos son mencionados en el reporte sobre Seguridad Pública: Medidas de Transformación (Diadema, Brasil) presentado en el Concurso "Ciudades para un futuro más sostenible" en el cual sumariamente se apunta: "los presupuestos participativos han abierto un diálogo constante entre gobierno y comunidades y ayudan a intensificar y expandir las aportaciones de la población a las discusiones sobre las arcas municipales" (Prefeitura de Diadema, 2006).

Es deseable contar con más datos correlativos entre los Presupuestos participativos y la disminución delictiva. A pesar de ello, al considerar que la Organización de Naciones Unidas indicó que el municipio de Diadema descendió 18 puestos en la estadística delincuencial, el hecho mismo es suficientemente estimulante para destacar esta hipótesis, dada las coincidencias estructurales, funcionales y ejecutivas de ambos procesos.

Si pudiera establecerse un primera equivalencia entre el proceso del Presupuesto participativo y la prevención comunitaria del delito, habría que decir que en el Presupuesto participativo se inicia con un acercamiento de las autoridades hacia la ciudadanía desde el momento en que se informa de la próxima 
implementación de dicho mecanismo de participación y se efectúa la correspondiente convocatoria para presentar proyectos. Ese acercamiento es equivalente al contacto y convocatoria de reuniones que tienen las autoridades de seguridad pública con y en las comunidades donde se generarán los programas de intervención en prevención del delito.

En segundo lugar la preparación y presentación de proyectos en ambos procesos se realiza bajo la fórmula de gobernanza como se ha descrito: se establecen redes de comunicación, negociación, inter-organización e inter-institucionalización para diseñar los proyectos que complementan recíprocamente las actividades del gobierno y las de los ciudadanos. En ambos casos los proyectos se enfocan a la solución de problemas y en esa medida cumplen con "la reconstrucción del control social del territorio por quienes lo habitan". Así por ejemplo, en el Manual sobre la aplicación eficaz de las Directrices para la prevención del delito de la Oficina de Naciones Unidas contra la droga y el delito (2011) puede hallarse que el control policial orientado a la comunidad ciudadana, aún en diversas versiones, tiene como elementos esenciales la implicación de la comunidad, la orientación a la solución de problemas y la descentralización (Oficina de Naciones Unidas..., 2011: 100), esos mismos elementos esenciales se encuentran en el Presupuesto participativo, dado que éste puede definirse como:

“... el mecanismo reconocido jurídicamente por el cual los ciudadanos ejercer el derecho de voz (para hacer propuestas de inversión pública con montos y programas), de voto (para decidir libre y deliberativamente entre sus planes y programas) de justicia social (para redistribuir proporcionalmente los bienes y servicios a cargo del gobierno) y de monitorización (de los recursos públicos a través de la transparencia y la rendición de cuentas), para definir las políticas públicas..." (Aguirre, 2014: 256).

En pocas palabras, las acciones a proponer, deliberar, votar y ejecutar por el financiamiento de un Presupuesto participativo pueden contener las acciones propuestas en los programas de prevención comunitaria.

En tercer lugar, las movilizaciones en ambos procesos presentan coincidencias individualizadas: desde la identificación y registro de los participantes, pasando por su capacitación, el desarrollo de talleres de trabajo, la evaluación y certificación de la viabilidad técnica, legal y económica de las actividades, la formalización de acuerdos y compromisos, hasta el seguimiento y registro de las acciones mismas.

En el caso de Diadema, las acciones coincidentes entre los Presupuestos participativos y la prevención comunitaria del delito fueron: la renovación o restitución de espacios urbanos; las actividades para jóvenes aprendices y la instalación de cámaras de vigilancia. También podrían coincidir, de haberse 
incluido en el Presupuesto participativo, las agencias y agentes de trabajo para dar seguimiento a los jóvenes en libertad condicional. Estas últimas actividades son altamente significativas en los programas de prevención, aunque obedecen al nivel terciario.

Las reconocidas criminólogas Joan Petersilia y Francis Cullen (2015) han insistido en que los presupuestos destinados a la construcción y manutención de prisiones se re-direccionen hacia las actividades comunitarias. En especial aquellas de reinserción social a través de los agentes encargados de dar seguimiento a la libertad condicional en las comunidades controladas (recuérdese, precisamente que en los Estados Unidos de Norteamérica la noción de prisión corresponde al nivel estatal, mientras que la de cárcel alude a la esfera del condado y que para el caso Latinoamericano equivaldría a las municipalidades comunitarias). Sin duda ello constituye un retorno al poder local no sólo en el plano presupuestal, sino también en el control policial y el servicio judicial.

El mejor desempeño policial también se da en los programas de prevención comunitaria al disponer del personal de seguridad pública como agentes comunitarios en vez de policías tradicionales. Así lo muestran los datos del cuadro comparativo de Kahn en relación a la experiencia brasileña en Sao Paulo que a continuación se reproduce.

Tabla I: Comparación entre la policía comunitaria y la policía tradicional

\begin{tabular}{l|c|c}
\hline $\begin{array}{c}\text { CUALIDAD EVALUADA } \\
\text { EN LA POLICÍA }\end{array}$ & $\begin{array}{c}\text { POLICÍA } \\
\text { COMUNITARIA }\end{array}$ & $\begin{array}{c}\text { POLICÍA } \\
\text { TRADICIONAL }\end{array}$ \\
\hline Más satisfactoria & $46.7 \% 34.6 \%$ & $39.6 \%$ \\
\hline Más solícita con la población & $50.6 \%$ & $42.9 \%$ \\
\hline Más educada & $53 \%$ & $17.9 \%$ \\
\hline $\begin{array}{l}\text { Más eficiente contra } \\
\text { el crimen }\end{array}$ & $21.4 \%$ & $29 \%$ \\
\hline Más riesgosa para el policía & $26.5 \%$ & $23.6 \%$ \\
\hline Más "dura" en su trabajo & $28.8 \%$ & $31.7 \%$ \\
\hline $\begin{array}{l}\text { Más satisfactoria para la } \\
\text { carrera policial }\end{array}$ & $39.1 \%$ & $10.3 \%$ \\
\hline Más sujeta a corrupción & $8.9 \%$ & $16.3 \%$ \\
\hline Más sujeta a violencia & $19.7 \%$ & Pá \\
\hline
\end{tabular}

Fuente: Kahn, Tulio (2004) Policía comunitaria: evaluando la experiencia de Sao Paulo. Chile: CED. 
El único elemento desfavorable para la policía comunitaria fue la mayor vulnerabilidad ante la violencia (último recuadro). Aunque en referencia a la prevención delictiva, -en opinión de los propios policías (el 20\% del personal policial y el $21.4 \%$ del personal policial comunitario)-, arrojó la opinión de que el patrullaje comunitario es más eficiente contra el delito. Es decir, hay una oposición entre la percepción ciudadana y la percepción de los propios policías entorno a la eficiencia de patrullaje contra el crimen. Ello es lógico porque la policía de prevención comunitaria no está adiestrada contra los delitos de narcotráfico, homicidio doloso, terrorismo, acciones paramilitares y los que comete el crimen organizado.

\section{LA LEGUA DE EMERGENCIA, SANTIAGO DE CHILE}

En La Legua de Emergencia, una comuna de San Joaquín al sur de la capital de la República de Chile, se realizaron, entre el año 2001 y 2003, actividades correspondientes a la prevención comunitaria del delito. Por su naturaleza participativa también podrían ser incluidas en la figura de la gobernanza y de los programas de un Presupuesto participativo.

En ese lugar del Cono Sur, las acciones de intervención se denominaron "líneas". Así por ejemplo, la primera línea se abocó a "generar un entorno más agradable para la convivencia entre vecinos" (Candina, 2006: 34). Línea que se tradujo en la reconstrucción de una zona multideportiva con $260 \mathrm{~m}^{2}$ de prados y $1,182 \mathrm{~m}^{2}$ de áreas verdes naturales. En otras áreas urbanas se dotó de luminarias peatonales y se agilizó la circulación al asfaltar tres pasajes y eliminar tres retenes físicos clandestinos.

Otra de las "líneas" abrió espacios para la participación y difusión de derechos. Se capacitó a veinte personas para tal efecto. Así mismo la línea de "expandir las oportunidades de recreación y expresión" implementó programas para alumnos y docentes en las que se realizaron actividades de pintura, literatura, convivencias familiares y apoyo al aprendizaje escolar. Se creó una "Casa de la Cultura para niños". Algunas otras líneas notables fueron "acercar la salud", que además de atender necesidades básicas de primeros auxilios capacitó a una docena de personas como agentes comunitarios en la prevención de la drogadicción. Otra línea fue "capacitación, empleo y desarrollo productivo", que generó más de una centena de empleos emergentes y capacitó a jefas de familia en telares, confección y lavado industrial, así como a la ciudadanía en general para la gestión de microcréditos. No se requieren muchas conjeturas para medir la enorme distancia entre estas acciones y los programas Broken Windows y Zero Tolerance. 
Las actividades realizadas en La Legua de Emergencia bien podrían clasificarse en acciones para la prevención social del delito. Al ser focalizadas a través de deliberaciones y consensos con los habitantes del territorio, caben dentro de la definición de la prevención comunitaria en el marco de la reconstrucción del control social del territorio por los habitantes del mismo. Aunadas a ellas se establecieron acciones típicas de control como la vigilancia y el patrullaje, ejercidos por juntas vecinales.

Lo anterior, en palabras de Candina (2006: 38) es un "regreso de las instituciones a los vecindarios marginalizados", es decir, el retorno del poder a las localidades de donde originalmente emana la soberanía ciudadana. Y aunque varias evaluaciones son disímiles entre la opinión de las autoridades y la comunidad respecto a la satisfacción de los programas (pues la ciudadanía desea que los policías tuvieran mayor incidencia en la limpieza e iluminación de la vía pública, la conservación de inmuebles abandonados en los vecindarios y, sobre todo, una concepción de la tarea policial como un trabajo para mejorar la calidad de vida); algunos puntos coincidentes son muy importantes para mostrar la gobernanza local. Uno de esos aspectos está referido a la propia actuación policial y del control ciudadano: "el patrullaje comunitario... parece tener un papel cierto en la reducción de la violencia policial e incentivar la participación comunitaria en las tareas de seguridad... la policía comunitaria ha mostrado un potencial para disminuir la violación de derechos ciudadanos por parte de la policía" (Candina, 2006: 56).

Destaca entonces la prevención comunitaria del delito porque transforma a la policía tradicional en una policía de mayor proximidad. Con lo cual incrementa el respeto a los derechos humanos de los ciudadanos y adopta la actitud de protección en vez de la beligerancia punitiva. La prevención, en lugar de la reacción ante el delito; y la promoción de la participación ciudadana, en lugar de la mera disuasión local de la infracción como pretenden las administraciones de Broken Windows y Zero Tolerance, son elementos comunes en la práctica exitosa de Chile y Brasil. Esos aspectos positivos marcan características del poder policial comunitario que muestran "el gobierno del pueblo, por el pueblo y para el pueblo", según el famoso discurso de Lincoln emitido en Gettysburg.

\section{BOGOTÁ, COLOMBIA}

Según el Manual sobre la aplicación eficaz de las Directrices para la prevención del delito, en el año 2007 la ciudad de Bogotá publicó su Libro blanco en el que "expuso sus objetivos a largo plazo para mejorar la seguridad y la calidad de vida de sus ciudadanos. Estableció además mecanismos de financiación conti- 
nua invitando a los distritos locales a solicitar fondos para emprender iniciativas de prevención" (Oficina de Naciones Unidas..., 2011: 43). Aunque la primera versión del Libro blanco es de enero de 2008 (UN-Habitat, 2008), no hay duda de que el exhorto a "establecer rubros específicos en los presupuestos locales y distritales para la prevención de la delincuencia" (2008: 54) es una versión aplicada e individualizada del Presupuesto participativo para la dimensión de la prevención comunitaria del delito en el marco de la gobernanza local. Versión que, como en muchos casos del Presupuesto participativo, no recibe dicha denominación.

La coincidencia de gobernanza entre las actividades del Presupuesto participativo y la prevención comunitaria vuelven a establecer la correlación teórica entre ambas formas de participación ciudadana aunque no se posean datos correlacionados en función de la baja en las tasas delictivas. De hecho, los programas de prevención generalmente se enfrentan al problema de cómo evaluarlos, es decir, ¿cómo evaluar lo que no sucede? En todo caso, habrá de enfatizarse las actividades coincidentes. A continuación se enumeran tanto las que siguieron a lo largo de los programas de 1993 a 2002, como las fueron vigentes hasta 2007:

a) "Plan desarme"; no sólo se reprimió la circulación de armas de fuego, sino que alrededor de 6,500 armas fueron entregadas a la policía voluntariamente.

b) Rehabilitación de espacios urbanos: tanto los aspectos inmobiliarios como de transporte fueron renovados en áreas específicas con mayor violencia (Avenida Caracas y zona de Cartucho).

c) "Frentes de Seguridad" fue un programa de comités de seguimiento de la delincuencia de barrio en el cual se fomentó la colaboración entre los policías de proximidad y los residentes. Se hizo a través de reuniones locales en las que se ventilaron los problemas de cada territorio.

d) Se crearon las Comisarías de familia como un medio para reducir la violencia doméstica, sobre todo la que afectaba a las mujeres toda vez que resultaban insuficientes las actividades de conciliación y mediación.

e) La profesionalización policial para la vigilancia preventiva (no sólo reacción).

f) Pactos de seguridad entre los actores institucionales y sociales

Después de las experiencias en Bogotá entre 1993 y 2008, para el año 2010 ya se había implementado en toda la República el Plan Nacional de Vigilancia Comunitaria por Cuadrantes, dependiente de la Policía Nacional de Colombia (2010). En dicho plan destaca la Tabla de Acciones Mínimas Requeridas 
(TAMIR) que involucra actividades de policía comunitaria y de acciones ciudadanas. De las actividades más exitosas cabe resaltar la continuidad de los Frentes de Seguridad Ciudadana que se ampliaron hacia nuevas redes entre la ciudadanía y la policía. Entre ambos impartían asesorías y visitas semanales a las escuelas en temas de resistencia, abusos y drogas. También fue notoria la implementación de "Escuelas de Seguridad Ciudadana" donde la colaboración entre los líderes de organizaciones vecinales y barriales con la policía resultó útil para ilustrar sobre la seguridad ciudadana pública. De igual manera se establecieron "Redes de apoyo y solidaridad" y "Redes de apoyo y comunicaciones" por las cuales la ciudadanía ejerce aspectos de gobernanza junto con las autoridades. Dentro de las actividades que pudieran llamar más la atención se encuentran los acercamientos a pandillas juveniles, a los adultos mayores en condiciones de población vulnerable y la "Policía Cívica Juvenil" que trabajó con niñas y niños los sábados por la mañana con objeto de enseñarles los rolles policíacos básicos y que, seguramente, en el futuro cercano serán los elementos comunicativos de información delictual más valiosos y factores multiplicadores de las acciones comunitarias.

Cabe destacar que gracias a las estrategias de planeación previas contempladas en la tabla TAMIR, una vez que fue terminada en su diseño y operación, el caso de Colombia es de los pocos que reporta instrumentación de indicadores para evaluar los efectos de impacto y no sólo indicadores de proceso de las acciones emprendidas en la prevención del delito. Por otra parte, la tabla TAMIR, como en Brasil y Chile, también muestra un desplazamiento de la policía tradicional hacia las policías de proximidad.

\section{TLALPAN, MÉXICO}

En México existen varias experiencias que por la naturaleza propia de la prevención comunitaria incluyen las perspectivas situacional, ambiental y social.

El Gobierno Municipal de la ciudad de Puebla, en su oportunidad, abordó el enfoque de prevención dirigido a evitar que los ciudadanos sean víctimas de delitos. Entre otras acciones y resultados elaboró el Manual ciudadano para la prevención del delito (Puebla, 2012) que consigna 13 delitos a prevenir, de los cuales la prevención en el trabajo, en el transporte público, en la calle o automóvil y en manejo de dinero, son de índole de prevención comunitaria.

El Estado de Aguascalientes, por su parte, también en el año 2012, desarrolló un "Plan de Prevención de las Violencias y la Delincuencia para el Estado de Aguascalientes" con un enfoque de prevención social que vinculó la participación ciudadana y las funciones policiales preventivas. Se destacó la participación ciudadana en los diagnósticos, las redes de información y colabo- 
ración para establecer sus tres ejes principales: creación o fortalecimiento de una red institucional, mejorar la vinculación para la generación de proyectos, aumento en la organización y participación ciudadana para la regeneración del tejido social.

Las líneas de acción propiamente comunitarias del segundo eje fueron: la campaña de difusión sobre temáticas de prevención (no conducir en estado de ebriedad, evitar la violencia familiar), que además proporcionaron información sobre derechos y obligaciones (salud sexual y reproductiva, derechos de la mujer), y la generación de un espacio de carácter no gubernamental para los integrantes de la red interinstitucional de prevención y la sociedad.

Las líneas de acción para el tercer eje fueron: fortalecer eventos y generar redes culturales a nivel estatal en grupos vulnerables; generar becas de educación artística profesional para los ganadores de los concursos artísticos; fortalecer los eventos deportivos, generando o fortaleciendo las redes sociales de grupos vulnerables; creación de un observatorio ciudadano a través de informantes clave en diversos sectores del estado, y la feria de la seguridad donde se difundieron los programas en materia de seguridad pública así como los productos y servicios para la prevención (Hernández y Zepeda, 2015).

Como puede conjeturarse, sólo las dos últimas acciones no podrían corresponder en estricto sentido a un programa de Presupuesto participativo, a menos que así lo decidiera la comunidad correspondiente y los financiaran. No obstante, todas las demás acciones enumeradas corresponden a la prevención comunitaria y son habitualmente -con mínimas variantes- programadas en las experiencias del Presupuesto participativo.

Aunados a estos y otros casos imposibles de enumerar por razones de espacio, el caso de la delegación Tlalpan, en la Ciudad de México, es significativo porque la Ley de Participación Ciudadana, promulgada en 2010, estableció en el artículo 83 la figura del Presupuesto participativo (Asamblea Legislativas del Distrito Federal, V Legislatura, 2010, artículo 83: 19) y en él consideró a la prevención del delito como uno de los tres rubros generales. En la reforma a dicha ley del 26 de agosto de 2011 los rubros generales se elevaron a cuatro y en la reforma del 13 de mayo de 2013, publicada en la Gaceta Oficial del Distrito Federal, la Asamblea Legislativa elevó a cinco los rubros de mayor importancia. En cada reforma la prevención del delito se conservó como un rubro general de vital importancia (Instituto Electoral del Distrito Federal, 2013: 16-18). Puede deducirse de lo anterior que el tópico de seguridad y prevención del delito es transversal, pues dentro de los proyectos específicos de la prevención se consideraron las luminarias y las alarmas, pero dentro de los otros rubros también destacan las luminarias, la recuperación de espacios públicos 
abiertos, espacios deportivos y culturales, gimnasios al aire libre, obras por colaboración (como una expresión práctica de la gobernanza) para mejorar la imagen urbana, las escuelas, las bibliotecas, los aspectos de higiene y salud pública, etcétera.

Lo anterior demuestra una correlación programática entre el Presupuesto participativo, la participación ciudadana, la gobernanza y la prevención comunitaria del delito. A pesar de ello, el enfoque de la prevención delictiva dentro del Presupuesto y la ciudadanía participativa no ha sido la perspectiva de abordaje, pues no se enfatiza el control social de un territorio por quienes lo habitan. Falta esa perspectiva específica para garantizar la transversalidad de la prevención.

\section{RESULTADOS DE LAS EXPERIENCIAS LATINOAMERICANAS: OBTENIENDO EL COMÚN DENOMINADOR DE LA PREVENCIÓN COMUNITARIA}

Si se desea tomar o recuperar el control para hacer efectiva la prevención comunitaria, las experiencias descritas coinciden en acciones dirigidas a evitar que se cometan delitos y también a que los ciudadanos no se ubiquen como sujetos vulnerables a la victimización. Es decir, presentan un común denominador al dirigirse a los niveles primarios (dirigida a la población en general) y secundarios (dirigida a potenciales victimizadores) de la intervención y no atienden el nivel terciario, según la conocida clasificación que Dammert (2005) aplicó para Latinoamérica.

Dentro del primer nivel puede considerarse una prevención disuasiva de nivel suave a través de campañas educativas, de gestión comunitaria, fuentes humanas de información sobre delitos y puntos de vulnerabilidad (inmuebles deshabitados, pasajes en abandono, atentados ecológicos) o contactos con ciudadanos cooperativos, informes sobre redes viales, alumbrado público, teléfonos o medios de comunicación públicos y de fácil acceso para el auxilio oportuno, instalación de rejas y alarmas, instauración de talleres culturales, artísticos, deportivos junto con comités de seguridad.

Dentro del segundo nivel, la prevención dirigida a que los ciudadanos no se hallen como sujetos vulnerables al delito, puede considerarse la prevención disuasiva de un nivel duro al establecer comités de rehabilitación para adictos con el objeto de evitar la reincidencia (Dammert y Lunecke, 2004: 47), brigadas de inspección a vehículos privados y públicos, cuerpos de control en el espacio público, retenes para revisión de personas, informes de inteligencia, reuniones con líderes que comandan frentes de seguridad que dan seguimiento a las 
denuncias. En un nivel muy superior de dureza, exclusivo de las fuerzas de seguridad pública, está la implementación operativa de patrullajes ciudadanos, guardias y grupos de vigilancia civiles o llanamente ciudadanos voluntarios ejerciendo las siente funciones policiales indicadas por el Consejo Nacional de Seguridad Pública de México. Las siete funciones policiales exclusivas para las fuerzas de seguridad pública son: armamento y tiro; capacidad física; defensa personal; detención y conducción de probables responsables; manejo de bastón policial; conducción de vehículos policiales; y operación de equipos de radio comunicación (Secretaría de Seguridad Pública, 2003).

Si se adoptan las tres teorías contemporáneas en la prevención del delito, pueden especificarse los elementos comunes de estas experiencias latinoamericanas. Ello se muestra en la Tabla II: Tabla de denominadores comunes en la prevención comunitaria.

Tabla II: Tabla de denominadores comunes en la prevención comunitaria

\begin{tabular}{|c|c|c|c|c|c|}
\hline $\begin{array}{l}\text { Prevención } \\
\text { Comunitaria } \\
\text { axial }\end{array}$ & $\begin{array}{l}\text { Diadema, } \\
\text { Brasil }\end{array}$ & $\begin{array}{l}\text { La Legua, } \\
\text { Chile }\end{array}$ & $\begin{array}{l}\text { Bogotá, } \\
\text { Colombia }\end{array}$ & $\begin{array}{l}\text { Tlalpan, } \\
\text { México }\end{array}$ & $\begin{array}{l}\text { Denominador } \\
\text { en común }\end{array}$ \\
\hline P. Social & $\begin{array}{l}\text { Salud pública. } \\
\text { Cultura de } \\
\text { legalidad. } \\
\text { Departamento } \\
\text { y Consejo } \\
\text { Municipal. } \\
\text { Presupuesto } \\
\text { participativo. }\end{array}$ & $\begin{array}{l}\text { Casa de la } \\
\text { Cultura. } \\
\text { Programa de } \\
\text { salud. } \\
\text { Capacitación } \\
\text { para empleo } \\
\text { y empresa. } \\
\text { Juntas } \\
\text { vecinales. }\end{array}$ & \begin{tabular}{|l|} 
Comités de \\
Barrio. \\
Comisarías de \\
Familia. \\
Pactos de \\
Seguridad. \\
Escuela de \\
Seguridad. \\
Policía juvenil. \\
Profesionaliza- \\
ción policial. \\
Presupuesto \\
participativo.
\end{tabular} & $\begin{array}{l}\text { Presupuesto } \\
\text { participativo. }\end{array}$ & $\begin{array}{l}\text { Presupuesto } \\
\text { participativo } \\
\text { enfocado a: } \\
\text { salud, cultura } \\
\text { y educación } \\
\text { cívica } \\
\text { institucionali- } \\
\text { zada en } \\
\text { seguridad. }\end{array}$ \\
\hline P. Ambiental & $\begin{array}{l}\text { Rehabilitación } \\
\text { de espacios } \\
\text { públicos }\end{array}$ & $\begin{array}{l}\text { Rehabilitación } \\
\text { de espacios } \\
\text { públicos }\end{array}$ & $\begin{array}{l}\text { Rehabilitación } \\
\text { de espacios } \\
\text { públicos y de } \\
\text { transporte } \\
\text { Redes y } \\
\text { acercamientos } \\
\text { a pandillas }\end{array}$ & $\begin{array}{l}\text { Rehabilitación } \\
\text { de espacios } \\
\text { públicos }\end{array}$ & $\begin{array}{l}\text { Rehabilitación } \\
\text { espacios } \\
\text { públicos }\end{array}$ \\
\hline
\end{tabular}




\begin{tabular}{l|l|l|l|l|l}
\hline $\begin{array}{l}\text { Prevención } \\
\text { Comunitaria } \\
\text { axial }\end{array}$ & $\begin{array}{l}\text { Diadema, } \\
\text { Brasil }\end{array}$ & $\begin{array}{l}\text { La Legua, } \\
\text { Chile }\end{array}$ & $\begin{array}{l}\text { Bogotá, } \\
\text { Colombia }\end{array}$ & $\begin{array}{l}\text { Tlalpan, } \\
\text { México }\end{array}$ & $\begin{array}{l}\text { Denominador } \\
\text { en común }\end{array}$ \\
\hline P. Situacional & $\begin{array}{l}\text { Cámaras de } \\
\text { vigilancia. } \\
\text { Recolección } \\
\text { de armas de } \\
\text { fuego. } \\
\text { Campañas } \\
\text { contra droga } \\
\text { yalcohol. }\end{array}$ & $\begin{array}{l}\text { Campañas } \\
\text { contra } \\
\text { drogadicción. } \\
\text { Patrullaje. }\end{array}$ & $\begin{array}{l}\text { Patrullaje } \\
\text { patrullaje en } \\
\text { transporte } \\
\text { público. }\end{array}$ & $\begin{array}{l}\text { Uso de } \\
\text { alarmas }\end{array}$ & $\begin{array}{l}\text { Campañas } \\
\text { antidrogas y } \\
\text { patrullaje } \\
\text { presencial o } \\
\text { mecanizado. } \\
\text { Policía de } \\
\text { proximidad. }\end{array}$ \\
\hline
\end{tabular}

Fuente: elaboración propia

Como puede observarse, en el común denominador de la prevención social domina el instrumento de participación ciudadana del Presupuesto participativo, los tópicos de salud y, sobre todo, la institucionalización de la participación ciudadana por la creación de instancias locales en departamentos, consejos, comisarías, escuelas y pactos o contratos sociales en torno a la convivencia y la seguridad. En cuanto a la prevención ambiental, la rehabilitación de espacios públicos es una constante ineludible, muy por encima de los diseños arquitectónicos de resguardo o vigilancia. Respecto a la prevención situacional, destacan las campañas contra los riesgos de la salud y la sociabilidad y en menor medida las tácticas de vigilancia, pero en todos los casos está presente la policía de proximidad.

\section{DISCUSIONES}

La participación ciudadana sería un sinsentido si no fuera útil para elevar la calidad de la seguridad ciudadana y pública al reducir la tasa delictiva. En esta afirmación hay tres variables que pueden y deben ser monitoreadas: los niveles de la participación ciudadana, la calidad de la seguridad y la tasa delictiva. Y a su vez, establecer las correlaciones entre unas y otras.

Para la prevención comunitaria del delito este ha sido el reto teórico y práctico más difícil de conseguir. En general, la literatura al respecto poco o prácticamente nada muestra de estas correlaciones. Las fuentes de información concernientes al caso de Bogotá son las más ilustrativas por contar con las mediciones temporales y comparativas sobre la baja en la tasa delictiva; de Diadema sólo existen reportes generales sin correlaciones precisas; Chile y México, siguiendo criterios internacionales, proponen un indicador general bajo la fórmula de 
contabilizar la medición de delitos por cada 100,000 habitantes. Esta última medida es relativa, pues no es proporcional ni realmente ilustrativa. En una misma ciudad, la medición de delitos resultará distinta al referirse a una comunidad residencial de clase socio-económica alta demarcada en 100,000 habitantes que en una comuna, favela o "barrio bravo" (según una popular expresión mexicana) limitada estadísticamente a igual número de habitantes. Los hábitats son distintos y los hábitos delictivos también, pues en las zonas residenciales podrían darse menos robos a transeúntes y más hurtos a residencias, mientras en las barriadas se contabilizarán menos secuestros y más delitos asociados a los pequeños beneficios inmediatos que buscan los infractores.

Para no tomar la prevención comunitaria del delito como un divertimento político o un esparcimiento de la ciudadanía privada en el escenario público de la gobernanza, debe imponérsele una responsabilidad social evaluable o monitorizada con indicadores. Las ciencias sociales, como las Ciencias de la Seguridad, la Criminología o la Victimología exigirían por lo menos dos tipos de indicadores: los que corresponden a las actividades en el proceso de la prevención y los correspondientes a los impactos.

Los indicadores de proceso pueden contabilizar, por ejemplo, el número y asistencia a las reuniones de planificación de los diversos programas que arriba se denominaron de nivel suave. La accesibilidad para establecer entrevistas de parte de los funcionarios gubernamentales con los ciudadanos participativos. El número de campañas de todo tipo, de informantes e informes, de acciones para recuperar y/o rehabilitar espacios urbanos, de actividades para proteger en la prevención ambiental o situacional a las personas y sus bienes a través de alarmas, rejas, luminarias, etcétera.

Los indicadores de impacto pueden ser, a su vez, subjetivos u objetivos. Dentro de los primeros cabe destacar las encuestas de satisfacción ciudadana o de percepción de la seguridad. En los segundos se encuentran los índices de criminalidad. Los índices de criminalidad, a su vez, pueden ser proporcionales o desproporcionales a los programas de prevención comunitaria. Así por ejemplo, los índices de criminalidad proporcionales han de medir los conflictos vecinales o entre pandillas, los conflictos de la población con la policía, los casos de robo con violencia a ciudadanos o con fuerza a inmuebles industriales, la violencia intrafamiliar o de género, la incautación de armas de fuego, drogas, autos o mercancías robadas, las lesiones por riñas, los accidentes de tránsito como infracciones administrativas, los delitos de abuso sexual, el asalto a bancos o comercios, el abigeato, el hurto a residencias y el tráfico de drogas al menudeo. Dentro de los índices no adecuados para evaluar la prevención comunitaria del delito se encuentra el homicidio doloso, el narcotráfico en altos 
volúmenes de trasiego, la trata de personas, el secuestro y las acciones del crimen organizado que pueden variar desde la producción de piratería masiva, pasando por el secuestro y la extorsión, hasta los delitos informáticos o el tráfico ilegal de especies animales o vegetales protegidas, la explotación forestal clandestina y la contaminación ecológica por el desecho o transporte inadecuado de residuos tóxicos. Obviamente en este rubro un sinnúmero de delitos también quedan excluidos del alcance de la prevención comunitaria, como son los fraudes mercantiles, los desfalcos financieros, las falsificaciones de documentos o papel moneda, las violaciones a contratos de trabajo, etcétera.

El reto ante los indicadores de impacto es doble. No sólo implica la obtención comparativa de datos antes y después de los programas de prevención, sino las evidencias de la correlación, la transparencia y rendición de cuentas gubernamentales. Datos que han de considerar la "cifra negra", es decir, los delitos que no se denuncian o no se registran. En general, el asunto no hace referencia a la eficacia de las autoridades de seguridad pública para consignar dichos índices, sino a su honradez en darlos a conocer o no hacer mal uso de los mismos. Así por ejemplo, respecto a la "Tamir" colombiana, la información llega a ser tan amplia que de esos datos Angarita afirma:

"se infiere igualmente una importante concentración de poder, situación que puede verse agravada en aquellos casos en los que, quienes controlan esa información, son funcionarios con prácticas corruptas y con vínculos a organizaciones criminales; por ello, esa concentración de información -y por tanto, de poder- puede constituir un alto riesgo para la propia seguridad de los habitantes del sector" (Angarita, 2014: 9).

Junto a este problema emerge otro igualmente alarmante: el uso excesivo de la fuerza por parte de la ciudadanía. Los patrullajes ciudadanos organizados en grupos de vigilancia civiles o los ciudadanos voluntarios con el ánimo de ejecutar funciones policiales, se han salido de control en más de alguna ocasión creando grupos paramilitares o las denominadas en México: "autodefensas". No se debe exhortar a la ciudadanía a rebasar los límites de la gobernanza, a participar en funciones exclusivas y reservadas para las instituciones de seguridad pública -por muy grande que sea el déficit gubernamental al respecto-. Una policía comunitaria conformada por ciudadanos sin la debida formación en dogmática policial, en el adoctrinamiento conforme al uso racional de la fuerza y en el eficaz adiestramiento para la persecución, detención, inmovilización y traslado de posibles delincuentes o sospechosos, o simplemente de infractores no penales sino administrativos, vulnera el Estado de Derecho tanto como la acción delincuencial misma. Ante este riesgo, debe limitarse la interactividad de la gobernanza y las facultades de la participación ciudadana con un 
delicado equilibrio en la desconcentración. El poder de la participación ciudadana debe ser potente, pero siempre legítimo y legal.

Cabe hacer notar que en las constantes y los comunes denominadores de la prevención comunitaria del delito ejercida por la gobernanza local, tanto en su planeación, ejecución y evaluación, se encuentran más presentes los indicadores de proceso que los de impacto. Que la mayoría de los indicadores de proceso son coincidentes con las acciones de participación ciudadana realizadas a través del Presupuesto participativo aunque no haya estudios explícitos de la respectiva correlación entre este mecanismo participativo y la tasa delictiva como indicador de impacto. Y que al menos existen menciones mínimas o implícitas del Presupuesto participativo en la prevención comunitaria.

Algunos aspectos negativos de la prevención comunitaria, sin embargo, se encuentran en ciertos efectos sociales. La reconstrucción o recuperación del control de un territorio acarrea la estigmatización socio-territorial, es decir, se genera una nueva categoría social o cultural, la de un "extraño", "foráneo" u "otro" que por su sola alteridad o diferencia es considerado peligroso. Todo aquel que vive fuera de las murallas divisorias de un barrio o zona residencial, que no está registrado por los sistemas de acceso o protección o no participa en la red de alarmas comunitarias corre el riesgo de ser criminalizado por mera exclusión.

Un efecto social de alto costo político consiste en que los miembros de la comunidad no dimensionen los alcances de la prevención y tengan expectativas sobre delitos que le corresponden de manera exclusiva a otras escalas del Estado. Por ejemplo, el tráfico de drogas a gran escala, el terrorismo, el contrabando de armas, las redes de trata, etcétera. En consecuencia, en los habitantes de las comunidades se generaría una frustración que los llevaría a la apatía ciudadana o, en el peor de los casos, a tomar acciones fuera de la legalidad; como por ejemplo, las ya mencionadas "autodefensas" mexicanas o los linchamientos.

La falta de indicadores de impacto sobre la tasa delictiva asociada a la prevención comunitaria ha sido una dificultad permanente, no sólo en América Latina, sino también en Estados Unidos. Destacados criminólogos como Crawford $(1997,1998)$ y Sherman (2002) reportaban estas carencias desde hace más de una década y se mostraban pesimistas ante la prevención comunitaria del delito. A pesar de lo anterior, los factores de éxito se identifican en la focalización de las intervenciones: tomar un asunto con especial concentración; ya sea la violencia intrafamiliar, la deserción escolar, la entrega de armas de fuego. También se deben focalizar los recursos humanos y el liderazgo personal e institucional de las autoridades con el deseo de establecer los programas con visión de continuidad. En contraste con las apreciaciones pesimistas, auto- 
res como Giller, Haggel, y Rutter (2000) por una parte, Krauskopf (1999) y Shaw (2001) por otra, coinciden en hacer notar experiencias exitosas cuando los aspectos de focalización han sido puntuales, especialmente el caso de trabajo comunitario con jóvenes. Quizá ello se deba a la adecuación de la intervención primaria y secundaria, pues en el caso de los jóvenes es más fácil el paso de ser victimarios o victimizados a convertirse en agentes de la prevención.

Un aspecto más a revalorar en la gobernanza de la prevención comunitaria es el rol de mando delegado en ciudadanos y el rol de género dentro del mando interno de los cuerpos policiales. Esta dimensión abre una futura línea de investigación porque los datos recabados en algunas experiencias muestran como factor importante de éxito el liderazgo civil y el femenino. Torres ha testimoniado que cuando las Coordinaciones de Seguridad Comunitaria han sido lideradas por civiles "con el fin de alejarlos del círculo de la corrupción de los mandos policiales... [y el mando táctico en la policía ha sido ejercido por una mujer] ....algo inusual en seguridad pública" (2005: 241), la confianza ciudadana se ha incrementado provocando mejores rendimientos del capital social.

\section{CONCLUSIONES}

En lo referente a la formación del capital social, la prevención comunitaria no presenta oposición desde el aspecto del control. Si, efectivamente, la prevención es 'la reconstrucción del control social del territorio por parte de quien lo habita', los habitantes de dicho hábitat son quienes constituyen el capital social. Capital que a largo plazo hace más efectiva y más barata -en relación a la fórmula costos/beneficios- la prevención que la reacción policial ante la presencia delictiva.

Más allá de la reconstrucción o recuperación del control de un hábitat por parte de sus mismos habitantes, la prevención comunitaria del delito aporta la solidaridad social. Aporta también mayores y mejores prácticas democráticas por la recomposición del tejido social y la efectiva y eficaz consolidación de la gobernanza. Con facilidad alcanza los niveles primarios (dirigida a la población en general) y secundarios (dirigida a potenciales victimizadores) de intervención preventiva y con una mayor estrategia podría alcanzar los niveles terciarios (enfocada a los victimarios para evitar las reincidencias).

Los diseños de prevención comunitaria muestran que los programas focalizados tienen más éxitos que los programas integrados (Dammert, 2005: 134). Por tanto, las relaciones entre la ciudadanía y las instituciones de seguridad pública deben planearse, organizarse e implementarse bajo el marco de la gobernanza y con el liderazgo coordinador de las autoridades. Además, los vínculos 
son altamente preferibles con las autoridades de escalas locales en vez de vincularse con funcionarios de otros rangos, pues las experiencias en contrario que se establecieron con autoridades de mayores esferas han mostrado impactos contraproducentes. Al respecto, debe notarse la excepción de Colombia, pues en ese país la Policía Nacional existe con un fuerte legado de la Policía Metropolitana y ello explica tanto el éxito en los indicadores de impacto como la facilidad para implementar en la formación policial y sus quehaceres diarios los programas de policía comunitaria.

Un desafío para la prevención comunitaria, así como para el Presupuesto participativo, son las fuentes de financiamiento para la operación de los programas. Los programas de Comuna Segura de Chile son ilustrativos; desde el año 2000 los criterios de priorización para el financiamiento se establecieron sobre líneas preferentes a la promoción de la participación comunitaria, el fomento de las organizaciones y formación de redes, la prevención de conductas delictivas o de riesgo social específicos, la gestión en grupos específicos, la organización de los proyectos con apoyo de asociaciones de distinta índole (escuelas, clubs, comunidades religiosas) y los proyectos elaborados por organizaciones juveniles y de adultos mayores. Éstos últimos son indicadores constantes de los procesos más deseables.

En términos concluyentes los factores generales para establecer programas exitosos, en la prevención comunitaria del delito a través de la gobernanza local, radican en siete denominadores que confirman la exigencia de institucionalizar la participación ciudadana. Esos comunes denominadores son: 1) la innovación, que recoge las iniciativas ciudadanas poco o nulamente imaginadas por las autoridades; 2) la precisión del impacto, es decir, la focalización a problemas concretos; 3) la asociación, entre ciudadanos individuales y grupos con la autoridad; 4) la gestión, que busca el ejercicio y defensa de derechos sociales y el seguimiento a las denuncias; 5) la sustentabilidad, a través de la viabilidad técnica, financiera y legal de los proyectos a aprobarse por los Presupuestos participativos; 6) el liderazgo ciudadano o de funcionarios comprometidos; y finalmente 7) la amplitud de inclusión y empoderamiento de cualquier miembro de la comunidad (niños e inmigrantes), no solo de los ciudadanos.

Como corolario final se deduce que cuando la participación ciudadana auxilia al Estado a proveer seguridad, entonces ambos logran hacer coexistir un máximo de libertad con un mínimo del ejercicio punitivo de parte de las instituciones de control. De manera que la seguridad pública se armoniza con la seguridad jurídica de cada ciudadano, un ideal largamente deseado por Baratta (2004) para evitar la transgresión de los derechos ciudadanos por las 
fuerzas de seguridad del Estado. Y sin duda alguna, la contemporánea prevención comunitaria del delito a través de la gobernanza local y sus vanguardistas instrumentos de participación ciudadana confirman la sabia tesis de Beccaria (1993:158): "Es mejor evitar los delitos que castigarlos".

\section{BIBLIOGRAFÍA}

Ackerman, B. (1999). “¿Un Neofederalismo?”. En J. Elster y R. Slagstad, Constitucionalismo y Democracia. Estudio introductorio de Alejandro Herrera, México: F.C.E., $205-207$.

Aguilar, L. (2007). "El aporte de la Política Pública y de la Nueva Gestión Pública a la gobernanza". Revista del CLAD Reforma y Democracia, No. 39, Caracas.

Aguirre, J. (2014). "Una contribución de Internet contra el déficit democrático: prerrogativas, riesgos, límites y alcances del Presupuesto participativo electrónico". Revista Internacional de Pensamiento Político, I Época, Vol. 9, 249- 265.

Angarita, P. (2014). "Políticas para enfrentar la violencia y la inseguridad en Colombia". Cuestiones de Sociología, No. 10, 1-13. Consultado el 11 de septiembre de 2015 de: http://www.cuestionessociologia.fahce.unlp.edu.ar/

Asamblea Legislativa del Distrito Federal, V Legislatura, (2010). Ley de participación ciudadana del Distrito Federal. México, D.F.

Baratta, A. (2004). Criminología crítica y crítica del derecho penal: introducción a la sociología jurídico penal. Argentina: Siglo XXI

Barnes, S. and Kaase M., (eds). (1979). Political Action. Mass Participation in Five Western Countries. Beverly Hills, CA: Sage.

Beccaria, C. (1993). Tratado de los delitos y las penas. Argentina: Editorial Heliasta S.R.L.

Cerrillo, A. (2005). La gobernanza hoy: 10 textos de referencia, Madrid: Instituto Nacional de Administración Pública.

Candina, A. (2006). Comunidad y prevención: una guía para el trabajo a nivel local. Chile: Centro de Estudios en Seguridad Ciudadana, Instituto de Asuntos Públicos, Universidad de Chile.

Crawford, A. (1997). The Local Governance of Crime: Appeals to Community and Partnerships. Oxford: Clarendon Press.

Crawford, A. (1998). Crime Prevention and Community Safety: Politics, Policies and Practices, Londres: Longman.

Dammert, L. y Lunecke, A. (2004). La prevención del delito en Chile. Una visión desde la comunidad. Chile: Centro de Estudios en Seguridad Ciudadana.

Dammert, L. (2005). "Prevención comunitaria del delito en América Latina: desafíos y oportunidades". Desafíos No. 13, 124-156. Bogotá, Colombia.

Ganuza, E. y Francés, F. (2015) "Citizen participation in Europe: a comparative analysis from the sociopolitical contexts". OBETS. Revista de Ciencias Sociales, vol. 10, No. 1, 235-260.

Glaser, B., y Strauss, A. (1967). The Discovery of grounded theory: strategies for qualitative research. Chicago: Aldine. 
Giller, H., Haggel, I., y Rutter, M., (2000). La conducta antisocial de los jóvenes, Cambridge: University Press

Hernando, F. (2008). "La seguridad en las ciudades: el nuevo enfoque de la geoprevención”. Scripta Nova. Revista Electrónica de Geografía y Ciencias Sociales. Barcelona: Universidad de Barcelona, 1 de agosto de 2008, vol. XII, núm. 270 (14). Consultado el 13 de agosto de 2015 de:

Hernández, F. y Zepeda, D. (2015). "El plan estatal de prevención social de la violencia y la delincuencia para el Estado de Aguascalientes: la participación ciudadana, la función policial preventiva y la confianza institucional". Archivos de Criminología, Seguridad Privada y Criminalística. Año 3, vol. V agosto-diciembre 2015. Consultado el 21 de agosto de 2015 de: www.somecrimnl.es.tl

Hernández-Sampieri, R., Fernández-Collado, C., Baptista, P. (2006) Metodología de la investigación. México: McGraw Hill.

Instituto Electoral del Distrito Federal (2013). Presupuesto participativo y planeación de proyectos. México: IEDF. Consultado el 20 de agosto de 2015 de:

Kahn, T. (2004). Policía comunitaria: evaluando la experiencia de Sao Paulo. Chile: CED.

Kelling, G. and Coles, C. (1998). Fixing Broken Windows: Restoring Order and Reducing Crime in Our Communities, USA: Touchstone Press.

Krauskopf, D. (1999) "Dimensiones críticas en la participación social de las juventudes", revisión del documento Participación y Desarrollo Social en la Adolescencia, Costa Rica.

Kooiman, J. (2005). "Gobernar en gobernanza”. En A. Cerrillo (comp.), La gobernanza hoy: 10 textos de referencia, Madrid: Instituto Nacional de Administración Pública.

Liddell, G. \& Scott, R. (1996). A Greek-English Lexicon, 9th ed., New York: Oxford Press.

Martí I Puig, S., Ortega, R., y Somuano, M. F. (eds.) (2011). La democracia en México. Un análisis a 10 años de la alternancia. Barcelona: Ediciones Bellaterra/El Colegio de México.

Núñez, L. (2011). "La prevención del delito a través de los paradigmas criminológicos”. En D. Ordaz y E. Cunjama (coord.). Criminología Reflexiva, Discusiones acerca de la criminalidad. México: Editorial Ubijus.

Organization for Economic Co-operation and Development (OECD). (2001). Citizens as partners. Information, consultation and public participation in policy-making. Paris: OCDE.

Oficina de Naciones Unidas contra la droga y el delito (2011). Manual sobre la aplicación eficaz de las Directrices para la prevención del delito. Serie de manuales sobre justicia penal. Nueva York: Naciones Unidas.

Osborne, D. and Gaebler, T. (1992). Reinventing Government. Massachutes: AddisonWesley.

Real Academia Española (1992). Diccionario de la Real Academia de la Lengua, 21ª. Edición. Madrid: RAE

Paniagua, A., Borunda, J., y Camargo, I. (2012). "Transparencia, participación ciudadana y gobierno electrónico: el caso del Gobierno Local de Ciudad Juárez, México". Sociedade e Cultura, 15: 1, Brasil, Universidad Federal de Goiás, 99-107. 
Pavarini, M. (1994). "Bisogni di Sicurezza e Questione Criminale". Rassegna Italiana de Criminología, Anno V - N. 4, Ottobre, Milano: Giuffrè Editore, 435-462.

Peters, G. y Jon P. (2005). "Gobernanza sin gobierno? Replanteándose la administración pública”. En A. Cerrillo (comp.). La gobernanza hoy: 10 textos de referencia, Madrid: Instituto Nacional de Administración Pública

Petersilia, J. \& Cullen, F. (2015) "Liberal but not stupid: meeting th promise of downsizing prisions". En Stanford Journal of Criminal Law and Policy, Winter 20142015. [Versión castellana en Criminología y Sociedad, Vol. 3, Núm. 4, 2014-2015, 11-116).

Policía Nacional de Colombia, Dirección General -Oficina de Planeación 2010 (2010). Estrategia institucional para la seguridad ciudadana: plan nacional de vigilancia comunitaria por cuadrantes (PNVCC). Aprobada el 5 de noviembre. Colombia: Gobierno Nacional.

Prats, J. (2005). "Modos de gobernación de las sociedades globales". En A. Cerrillo (comp.). La gobernanza hoy: 10 textos de referencia, Madrid: Instituto Nacional de Administración Pública.

Prefeitura de Diadema (2006). Seguridad Pública: Medidas de Transformación (Diadema, Brasil). Consultado el 20 de agosto 2015 de: recuperado 20 de agosto 2015

Puebla, Gobierno Municipal, Consejo Ciudadano de Seguridad Pública, Secretaría de Seguridad Pública y Tránsito Municipal (2012). Manual ciudadano para la prevención del delito. México: IMPLAN.

Secretaría de Seguridad Pública, Estados Unidos Mexicanos (2003) Manual de conocimientos básicos de la función policial. México: Sistema Nacional de Seguridad Pública.

Shaw, M. (2001). Invirtiendo en los jóvenes 12-18 años: enfoques internacionales para prevenir el crimen y la victimización, Montreal: Centro Internacional para la Prevención del Crimen (CIPC).

Sherman, L. (2002). "Trust and confidence in criminal justice". National Institute of Justice Journal. No. 248, 22-31

Sozzo, M. (2000) "Seguridad urbana y tácticas de prevención del delito". Cuadernos de Doctrina y Jurisprudencia Penal, Año VI, No. 10-B. Argentina; Ed. Ad-Hoc, 17-82.

Strauss, A., y Corbin J. (1990). Basics of qualitative research: grounded theory procedures and techniques. California: Sage.

Torres, B. (2005) "Barrios trabajando: una experiencia participativa de seguridad comunitaria y desarrollo social”. En E. López Estrada y R. Ferreira (Coord.). Pobreza, empleo y participación ciudadana: aportes para la política social. México: Universidad Autónoma de Tamaulipas, Universidad Autónoma de Nuevo León, 228-246.

UN-Habitat Programa Ciudades Más Seguras (2008). Libro Blanco de la Seguridad Ciudadana y la Convivencia de Bogotá Colombia: Alcaldía Mayor de Bogotá D.C.

Van Dijk, J. (1990). "Crime Prevention Policy: Current State and Prospects”. En G. Kaiser y H. J. Albrecht: Crime and criminal policy in Europe, Criminological research report, Vol. 43, Max Planck Institute, Freiburg, 1990, 205-220. 
Vallès, J. M. (2000). Ciencia política. Una introducción. Barcelona: Ariel.

Wilson, J. and Kelling, G. (1982). "Broken Windows". En The Atlantic Monthly, march.

JORGE FRANCISCO AGUIRRE SALA es mexicano, doctorado en Filosofía e investigador en el Instituto de Investigaciones Sociales de la Universidad Autónoma de Nuevo León, México. Autor de más de cien artículos y libros, sus aportaciones recientes versan sobre la democracia líquida, la participación ciudadana y la gobernanza, aplicadas a la construcción de políticas públicas en aspectos de justicia social, ecología y seguridad. Autor de la propuesta Ciudadanía Mediática, Perspectivas de la Comunicación, 2011. Entre sus publicaciones destacan: "La Democracia Líquida", UOC, 2016; "Los límites de la representatividad política y las alternativas de la democracia líquida", en Revista Internacional de Pensamiento Político, 2015; "Necesidad y condiciones de la democracia líquida: los primeros pasos en México", en Revista Culturales, 2016. Su vida y trabajo académico están consignados en 2000 Outstanding Intellectuals of 21st Century del International Biographical Centre, Cambridge, Inglaterra.

Recibido: 12/09/2015

Aceptado: 05/09/2016 